\title{
Identificação de variáveis que afetam o envelhecimento: análise comportamental de um caso clínico
}

\author{
Identification of aging variables: a clinical \\ case report behavioral analysis
}

\author{
Elissa BATTINI ${ }^{1}$ \\ Evelise Martinelli MACIEL ${ }^{2}$ \\ Mariza da Silva Santos FINATO ${ }^{3}$
}

\begin{abstract}
Resumo
O objetivo desta pesquisa foi identificar e analisar as variáveis que influenciam a adaptação do indivíduo ao processo de envelhecimento. Para tanto foi realizado um estudo de caso que identificou algumas variáveis que, quando presentes, podem tanto aumentar quanto diminuir a probabilidade de adaptação adequada à velhice. Dentre as que podem aumentar a probabilidade de um envelhecimento bem-sucedido, destacam-se: autonomia, auto-aceitação, redes de apoio, crença religiosa e propósitos de vida. Entretanto outras características podem diminuir essa adaptabilidade, tais como: negação da velhice, isolamento, postura místico-religiosa conformista e alienação do presente. O resultado do estudo corrobora tal levantamento, de modo que a entrevistada parece ter se adaptado à velhice em virtude das habilidades desenvolvidas ao longo de sua vida, assim como das contingências atuais.
\end{abstract}

Palavras-chave: adaptação; envelhecimento; estudo de caso.

\begin{abstract}
The objective of the present study was to identify and analyze variables which facilitate and difficult the individual adaptation during the aging process. A case study was made to identify some variables that can increase and decrease the probability of aging adaptation. Among those aspects that can increase the probability of a well-succeeded aging are: autonomy, self acceptance, support network, religious belief. The variables that influence negatively the aging process are: aging denial, isolation, conformist mystical religious posture and present alienation. The results confirm the study as the interview seems to be adapted to the aging process, regarding to the developed abilities during lifetime, and the actual contingencies.
\end{abstract}

Key words: adaptation; aging; case study.

Nas últimas três décadas, a Psicologia do enveIhecimento vem se desenvolvendo rapidamente no campo científico internacional devido a um conjunto de fatores, dentre eles o envelhecimento populacional. Juntamente com o progresso científico, tem-se a mudança gradual da mentalidade em relação à velhice,

$\operatorname{cov}$

1 Mestranda, Departamento de Psicologia Geral e Análise do Comportamento, Universidade Estadual de Londrina. Londrina, PR, Brasil,

2 Acadêmica, Curso de Psicologia, Universidade Estadual de Londrina. Londrina, PR, Brasil.

3 Professora Doutora, Departamento de Psicologia Geral e Análise do Comportamento, Universidade Estadual de Londrina. Rodovia Celso Garcia Cid, km 380, Campus Universitário, 86051-990, Londrina, PR, Brasil. Correspondência para/Correspondence to: M.S.S. FINATO. E-mail: <maritza@londrina.net>. 
que passa a ser considerada uma fase no desenvolvimento e não exclusivamente de incapacidades e perdas (Neri, 1995). Por conta dessa nova demanda, estudos que busquem identificar fatores que contribuam para um envelhecimento bem-sucedido - com a preservação da saúde, com a independência física e cognitiva e a autonomia moral - mostram-se pertinentes.

Segundo Haydu (2003), adaptar-se às variações do meio ambiente e sobreviver a elas é um grande desafio para qualquer organismo vivo. O ser humano enfrenta esse desafio desde o momento do nascimento até a morte. Como a infância, a adolescência e a vida adulta são etapas do desenvolvimento do indivíduo, a velhice também o é, e, como tal, requer adaptação constante às modificações que o meio impõe.

O desenvolvimento humano é um processo multideterminado, ou seja, não é caracterizado por processos isolados de crescimento e declínio (Neri, 1995). A compreensão do desenvolvimento e da adaptação do indivíduo ao seu meio deve envolver a análise de todas as suas interações, dentre elas: as contingências filogenéticas (determinadas pela herança genética), as ontogenéticas (história de vida do indivíduo) e as culturais (Haydu, 2003). Assim, ao longo do processo de desenvolvimento, eventos ambientais vão se sobrepondo, tornando aquele indivíduo único. O envelhecimento configura-se então como uma experiência heterogênea, que dependerá de como o indivíduo organiza sua vida a partir das circunstâncias histórico-culturais, da incidência de patologias durante o envelhecimento normal e da interação entre fatores genéticos e ambientais (Neri, 1995).

Embora existam grandes diferenças individuais no processo de envelhecimento, Baltes e Silverberg (apud Néri, 1995) estabelecem três domínios gerais que devem ser considerados: 1) o aumento nas perdas físicas, em que a saúde tende a ser um problema crescente; 2) a tendência de as pressões e as perdas sociais se acumularem, sendo comum nas sociedades ocidentais oferecerem-se poucas oportunidades de novos papéis sociais para o idoso; 3) a diminuição do tempo cronológico, que pode levar à perspectiva iminente da finitude, favorecendo a mudança no sentido de vida.

Assim, mesmo que o envelhecimento bem-sucedido seja multifacetado, grande parte dos idosos

456 poderá vivenciar os domínios acima, de forma que interferir em tais variáveis poderia ser pertinente na medida em que a mudança ocorreria nos níveis gerais do envelhecimento e não em suas particularidades. Programas de reinserção dessa população, por exemplo, poderiam ser adequados.

A aposentadoria é, para muitos, um dos fatores que contribui para as perdas sociais e dos papéis exercidos na sociedade, visto que o trabalho, geralmente, possui grande relevância na vida do indivíduo. Segundo Tavares, Neri e Cupertino (2004, p.98), “a perda do papel e a concomitante perda da identidade gerariam estresse, ansiedade e predisposição à depressão". Esses mesmos autores afirmam que a partir da diminuição do status social e da modificação dos papéis sociais exercidos, restam somente duas saídas para o indivíduo: o isolamento ou a busca de novos papéis no meio familiar. São novas contingências de vida sobre as quais o indivíduo precisará operar de forma a adquirir outros repertórios pessoais, caso contrário poderá deixar de interagir com pessoas que lhe eram próximas e importantes. É provável que seu mundo tenha ficado mais reduzido, que seus interlocutores tenham se afastado, criando, assim, o ambiente ideal para o isolamento social. Dessa forma, alguns indivíduos se aposentam sem encontrar dificuldades de adaptação, enquanto outros necessitam de um maior esforço para se ajustarem a essa nova fase da vida.

É o padrão de comportamento do indivíduo, no entanto, que irá dificultar ou facilitar sua adaptação à velhice, que será a conseqüência de seu modo de vida anterior. Skinner e Vaughan (1985, p.27) afirmam: "se viver bem a vida é depender de coisas como traços de caráter ou modos de pensar, porque então as pessoas que vivem bem enquanto jovens não vivem também assim quando são mais velhas?"

As pessoas podem tentar estabelecer planos para ter um envelhecimento bem-sucedido. Para Skinner e Vaughan (1985), tornar-se idoso é como ir morar em outro país. Antes de se mudar, portanto, é essencial conhecer a língua falada, o tipo de comida e os hábitos da nova moradia. Dessa forma, a adaptação se torna mais fácil. O importante é enxergar que essa é uma fase do desenvolvimento como outra qualquer e, como tal, possui tanto aspectos positivos quanto negativos. Segundo os autores, não há como negar que, com o envelhecimento, os sentidos acabam se tornando menos precisos e os músculos mais fracos, mas para 
isso os avanços da ciência existem e devem ser utilizados:

Alguém já disse que se você quiser saber como se sente um velho, embace os óculos, tape os ouvidos com algodão, calce sapatos pesados e folgados demais para seus pés, ponha luvas e tente, mesmo assim, levar uma vida normal. Algumas das imperfeições da velhice podem ser compensadas de várias maneiras. Óculos e aparelhos para surdez servem para isso. Mas também podemos tirar proveito de um mundo planejado, de modo a nos comportarmos razoavelmente nele, a despeito de nossas deficiências (Skinner \& Vaughan, 1985, p.35).

Assim, pode-se dizer que o behaviorismo radical entende a velhice como sendo um produto de todos os comportamentos e variáveis que afetam o indivíduo ao longo de sua vida: a educação que Ihe foi dada, a religiosidade, a cultura e o ambiente familiar. Considera se o indivíduo foi usuário de drogas, de tabaco, de álcool e se tinha uma vida sedentária. Leva-se em conta se tal indivíduo possuía um círculo social ou se vivia isolado; se o trabalho era o único reforçador e agora é obrigado a se aposentar; se esse indivíduo é alguém que costuma estabelecer objetivos ou resigna-se diante das dificuldades da vida, observa até mesmo se foi acometido por doenças etc. Tais variáveis permitirão que o indivíduo se adapte mais ou menos à velhice, dependendo das condições ambientais que Ihe afetaram e que continuarão presentes ao longo de seu envelhecimento.

De acordo com Freire (2000), a questão do bem-estar na velhice é algo que vem sendo discutido. Os estudos apontam que se determinadas variáveis estiverem presentes, a chance de adaptação à velhice aumenta consideravelmente. Entre elas, destacam-se:

1. Autonomia: Guilhardi (2002, p.83) considera que a autonomia está intimamente relacionada à autoconfiança, ao passo que uma pessoa autoconfiante sabe quais comportamentos deve emitir para obter conseqüência positivas. Assim, ser autônomo significa ter habilidades para pensar e agir de determinada maneira e avaliar as situações com seus próprios pontos de vista, fazendo escolhas, tomando suas próprias decisões, o que faz com que essas pessoas sintam que possuem controle sobre suas vidas. Godstein (2002) enfatiza a importância do senso de controle para o bem-estar dos indivíduos em todas as idades, assim como os gerontólogos consideram que o nível de independência do sujeito está muito ligado ao conceito de saúde.

2. Redes de apoio: o ser humano é gregário por natureza. Perder o contato com outras pessoas é sinônimo de reclusão e de perda de interesse pela vida. Para uma adaptação adequada é imprescindível que haja um ambiente em que o idoso possa se sentir como parte integrante de um grupo social. Além disso, Starling (1999) aponta para o fato de que o estar inserido em um grupo social retarda o processo de envelhecimento comportamental.

3. Auto-aceitação: segundo Freire (2000), implica uma atitude positiva do indivíduo em relação a si próprio e à sua história de vida, aceitando características positivas ou negativas, como também sua nova condição como idoso. Uma parte da auto-aceitação é caracterizada pela auto-estima, um sentimento aprendido que se desenvolve durante toda a vida de uma pessoa, ao passo que o indivíduo em si é tido como reforçador em relacionamentos sociais e não somente seus comportamentos (Guilhardi, 2002, p.71).

4. Propósitos de vida: significa continuar estabelecendo objetivos na vida que impulsionem o indivíduo a continuar vivendo.

5. Crença religiosa: de acordo com Cavalcante (2002), o fato de a velhice ser considerada a última etapa da vida faz com que ocorra um aumento da freqüência sobre o pensar na morte e, sobretudo, a respeito do que vem depois dela. Se a questão da finitude parecia longínqua, pouco pensada; na velhice, torna-se mais próxima e até real. A morte de pais, de parentes e de amigos remete imediatamente à própria morte. $\mathrm{O}$ retorno a uma prática religiosa passa a ser mais evidente e sentida como também indispensável. Não é sem razão que muitos consideram a velhice como a etapa em que um balanço da vida é necessário e inevitável.

Considerando a importância de tais características e estando elas presentes no cotidiano das pessoas, percebe-se o aumento da probabilidade de uma melhor adaptação à velhice. No entanto, certas variáveis, se presentes, podem ser pouco adaptativas ao novo contexto: a passagem para a velhice. Mira y Lopez (apud Cavalcante, 2002) destacam as seguintes variáveis:

1. Agarrar-se ao passado: o indivíduo que se agarra ao passado passa a viver de recordações. Aliena- 
-se do presente. Suas referências estão todas nos anos anteriores. Nada mais tem valor senão as coisas de antigamente, o que faz com que ele se afaste daqueles que o cercam, visto que não aceita as condições atuais.

2. Negar a velhice: aquele que ignora a velhice tenta encontrar desesperadamente a fonte da eterna juventude. Busca de todas as formas parecer jovem. Observa-se que atualmente há um culto exagerado à juventude e um desprezo ao idoso. Além de o jovem ser cultuado, o velho é rejeitado.

3. Isolar-se: o indivíduo passa a ser introspectivo. Submerge em tristeza e desolação. Já que não desperta paixão, busca ao menos a compaixão;

4. Adotar uma atitude místico-religiosa, assumindo uma postura conformista: a religião é abraçada como forma de renúncia, resignação conformista e alienação. Fechada num sistema de crença maniqueísta, a pessoa se sente passiva e descompromissada com a vida, como se Deus fosse o responsável por tudo que Ihe acontece.

Desse modo, o objetivo do presente estudo é analisar o envelhecimento sob o enfoque comportamental, assim como realizar o levantamento de variáveis que possam facilitar ou dificultar a adaptação do indivíduo ao processo de envelhecimento.

\section{Método}

Para a formulação deste artigo, foi utilizado o estudo de caso único, baseado no relato verbal de uma mulher aposentada, de sessenta e cinco anos. A escolha pelo sexo feminino se deve ao fato da maior longevidade da mulher em relação ao homem, pois, segundo Fraiman (1995), as mulheres vivem por volta de seis a oito anos a mais que os homens. Foram realizadas três entrevistas semi-estruturadas que abordaram aspectos da história pessoal passada, presente e perspectivas futuras. Para a construção do artigo foram selecionadas frases da participante e a sua linguagem foi mantida e mapresentada entre aspas para a ilustração das análises e dos comentários.

\section{Estudo de caso}

"A" é uma mulher de 65 anos. Mora com seu marido e tem quatro filhos, todos casados. É professora aposentada, atua como ministra da igreja, dá aulas particulares de matemática efaz artesanatos para vender. Considera-se uma pessoa bastante ativa e batalhadora.

\section{História de vida}

Segundo a entrevistada, sua mãe foi uma pessoa exigente e punitiva: "minha mãe batia na gente por qualquer coisinha, nós tínhamos medo dela. Se ela dissesse para buscar palha para acender o fogo, ia correndo senão apanhava". Apesar disso, "A" relata que tinha um bom relacionamento com ela, "dava para sentir o amor dela pela gente". A mãe tinha estudado pouco, acreditava que a filha deveria estudar e a incentivava.

O pai não foi uma figura presente na educação de "A"; ele era analfabeto e achava que não era preciso estudar, pois acreditava que a preocupação da mulher deveria ser exclusivamente o casamento, não os estudos, e punia a filha se a visse estudando:"estudava quietinha, se meu pai soubesse, vinha e me batia". No entanto, "A" queria continuar estudando apesar das dificuldades encontradas: a falta de incentivo do pai e o fato de morar em um sítio longe da escola; por isso " $\mathrm{A}$ " teve de produzir modificações no seu ambiente, como vender ovos e frangos para comprar material escolar, estudar escondida do pai e andar longas distâncias até a escola." A" relatou que era a melhor aluna da sala e que seu caderno era um "exemplo de capricho".

Depois do casamento, seu marido também não a apoiava nos estudos, por isso " $\mathrm{A}$ " precisou interromper a faculdade várias vezes para cuidar dos filhos, "faculdade de quatro anos, eu fiz em oito." "A" concluiu quatro cursos superiores: Matemática, Ciências Contábeis, Pedagogia eTeologia. Também fez duas especializações: Supervisão Escolar e Espiritualidade. Trabalhou como professora de matemática e também na coordenação e na direção do colégio em que trabalhava.

"A"relatou que, devido ao modelo de educação exigente de seus pais, ela também foi uma mãe exigente, punitiva e controladora:"eu batia e chamava meus filhos de burros, eu era rígida com relação aos estudos e a sair de casa, eles tinham horário para voltar, se não voltavam, ia buscar". Atualmente, ela acredita que falhou na educação de seus quatro filhos, pede-lhes perdão quando conversam a respeito, diz que estava "aprendendo a ser mãe" e procura orientá-los na educação 
dos netos. "A" não concorda com a educação que um de seus filhos dá ao neto. Relatou que ele, além de ser rígido com os filhos, não Ihes demonstra amor e carinho, nunca faz um elogio a eles. Em relação à sua filha mais nova, diz que educa os filhos de forma correta, não utiliza punições e demonstra-Ihes afeto.

Foi possível identificar que "A" convive com diversos grupos de pessoas - os familiares, as pessoas da igreja e as da escola - e encontra os filhos nos finais de semana. Com o grupo da igreja, encontra-se todos os dias, mas o contato se restringe à igreja. Já com as pessoas da escola, ela diminuiu o contato após a aposentadoria, mas fazem duas reuniões por ano para se encontrarem e algumas Ihe telefonam. "A" demonstra se preocupar com todas as pessoas com quem convive, sendo freqüentemente solicitada: "se vejo que uma pessoa está doente, rezo; se precisa de uma coisa, largo tudo e vou acudir".

Os valores de vida que "A"preserva são a honestidade, a pontualidade e a responsabilidade,"se assumo um compromisso, mesmo se for para juntar o Céu e a Terra, tenho que cumprir; e horário, se for às oito horas éàs oito, sou muito enérgica comigo mesma, até judia da gente ser assim". Relata que durante toda sua vida só se dedicou aos filhos, ao serviço, aos estudos e à igreja, deixando para segundo plano sua saúde: "se tivesse compromisso, saía do médico e ia fazer minha obrigação". Considera que se tivesse agido de forma diferente teria sido melhor, pois teria se divertido mais.

Percebe-se por meio das falas de "A"um conflito, pois mesmo acreditando que o melhor é agir diferente de como agiu até agora em sua vida, seus valores continuam os mesmos e continua tendo muitas das mesmas atitudes.

Nota-se que a religiosidade de "A"foi aumentando com o passar dos anos; apesar de sempre ter freqüentado a igreja, disse que anteriormente entendia "tudo errado, eu ia para namorar". Aos trinta e três anos fez um encontro de casais e a partir daí começou a desenvolver de forma gradativa sua religiosidade, participando de grupo de orações. As falas de " $A$ " demonstram uma presença forte da religião em sua vida:"me apego muito a Deus, eu levo todos os meus problemas a Jesus, Ele é quem dirige minha vida, tudo o que eu tenho que fazer". Hoje é ministra eucarística de sua igreja, trabalha em várias missas durante a semana e tem reuniões quase todos os dias. Também participa de encontros religiosos e coordena o grupo de oração do prédio em que mora.

O objetivo de "A", desde a infância, foi estudar para ser professora, ter uma casa para morar e dinheiro para viver. Relatou que nunca quis ser rica e hoje se sente realizada com seus propósitos alcançados. Há cinco anos está aposentada, continua a dar aulas de catequese e aulas particulares de matemática. Apesar de ainda gostar de estar em contato com alunos, seu objetivo mudou: ela quer continuar cuidando de sua saúde e relacionando-se bem com sua família. Demonstrou uma preocupação em estar perto da família por acreditar que está chegando cada vez mais perto da morte.

Sendo assim, "A" relatou que durante sua vida aprendeu a ser mais calma, em um desentendimento procura conversar para compreender a outra pessoa e a perdoa. Antes, pelo contrário, quando se desentendia com alguém, era capaz de "bater nessa pessoa e de vingar-se dela".

\section{Discussão}

De acordo com Skinner e Vaughan (1985), o padrão de comportamento do indivíduo tem implicações sobre o quanto ele irá se adaptar ao envelhecimento. Dentro dos limites que o envelhecimento fisiológico impõe, as pessoas agem e pensam como jovens ou como velhos em função do que acontece a elas e do que elas fazem. Dessa forma, indivíduos que tenham condições de se adaptar às novas transformações que o envelhecimento Ihes coloca terão, provavelmente, mais condições de serem bem-sucedidos ao envelhecer.

Embora o comportamento seja multideterminado, produto da interação entre contingências filogenéticas, ontogenéticas e culturais, este estudo analisa variáveis que possam favorecer o envelhecimento bem-sucedido da participante.

Em relação à autonomia, observou-se que " $A$ " pode ser considerada uma pessoa independente porque avalia as situações e toma suas próprias decisões. Tal característica é considerada relevante porque os idosos, segundo Goldstein (2002), geralmente perdem o poder 
de decidir sobre sua vida, trazendo a sensação de inutilidade e incapacidade e de que o controle de sua vida se encontra na mão de outros. "A", entretanto, é autoconfiante, pois tem habilidades para saber quais comportamentos deve emitir para obter conseqüências positivas. Isso pode ser observado pelas verbalizações da participante: "sou uma pessoa que não é qualquer probleminha que me afeta, vou lá e resolvo","considero minhas opiniões importantes porque soluciono o que aparecer na minha frente","'quando tenho que falar algo, eu chego na pessoa e falo".

O sentimento de autoconfiança, de acordo com Guilhardi (2002), está associado a comportamentos bem-sucedidos, ou seja, a pessoa age no ambiente e produz conseqüências positivas que fortalecem tais comportamentos. As pessoas autoconfiantes tornam-se autônomas e independentes, "já que se basta para conduzir sua vida e para enfrentar as dificuldades do cotidiano e, assim, desenvolvem sentimentos de segurança, de satisfação, de coragem e etc." (Guilhardi, 2002, p.83).

A autonomia e a independência trazem vantagens ao indivíduo por sua capacidade de fazer escolhas, de tomar decisões baseadas em seu próprio ponto de vista e de emitir comportamentos de controle sobre o ambiente. Esses comportamentos de controle estão relacionados, segundo Goldstein (2002), com a habilidade de influenciar situações ou seus efeitos por meio de ações selecionadas e específicas e é essencial para o bem-estar dos indivíduos em todas as idades. É possível perceber na história de A. comportamentos de domínio sobre o ambiente desde a infância, quando atuou nas contingências presentes, conseguindo seguir seus estudos até hoje, o que provavelmente Ihe auxiliará nessa nova fase da vida: a terceira idade. Segundo Goldstein (2002, p.56):

A perda de controle está associada a problemas de auto-estima, à redução de bem-estar e à depressão. Essa relação pode se tornar ainda mais exacerbada na velhice, quando muitos fatores ambientais relacionados ao aumento da idade (por exemplo, a perda das funções sociais ou de amigos e familiares, mudanças em normas sociais e em expectativas) provocam um grande impacto na percepção da própria competência e na capacidade de prever resultados das próprias ações.
Em se tratando da variável redes de apoio, pode-se notar que "A" continua sendo parte integrante de seu grupo social. O que acontece geralmente junto com a aposentadoria é uma perda social, no entanto, na vida de " $A$ " isso não é observado. Mesmo diminuindo o relacionamento que tinha com as pessoas da escola em que trabalhava, ela se inseriu em um novo contexto social: a igreja. Além desse grupo, ela possui uma rede de apoio forte, que são seus filhos, que se preocupam com ela, e os amigos que sempre lhe telefonam. Percebe-se que " $A$ " dentro dos grupos sociais se comporta ativamente e estabelece relações empáticas, fator que facilita o bem-estar durante a velhice e que atrasa o processo de envelhecimento comportamental. Segundo Starling (1999, p.221):"... a perda da competência social pode ser prematuramente instalada em função da exclusão do idoso do controle social exercido através de contingências de reforçamento precisas que atuam nas etapas anteriores de vida do indivíduo".

A auto-aceitação, segundo Freire (2000), implica atitude positiva do indivíduo em relação a si próprio eà sua história de vida, aceitando características positivas ou negativas, como também sua nova condição de idoso. Nota-se que "A" parece não ter problemas em relação a si mesma; apesar do envelhecimento, tal atitude parece estar ligada à auto-estima positiva construída ao longo de sua história. A auto-estima, segundo Guilhardi (2002, p.71), " é o produto de contingências de reforçamento positivo e de origem social". Esse sentimento traz vantagens ao indivíduo pelo fato de desenvolver comportamentos de tomar iniciativa e de produzir maior variabilidade comportamental e de criatividade. Essas habilidades possuem grande importância quando há modificação das contigências ambientais para que o indivíduo possa responder de forma diferenciada ao novo contexto, o que acontece na fase da velhice, com a aposentadoria e com as perdas físicas e afetivas.

Além do sentimento de auto-estima, outro aspecto que caracteriza a auto-aceitação é o reconhecimento de forma positiva de sua história de vida, incluindo tanto aspectos bons quanto ruins. Essa característica aparece várias vezes na fala de "A". Ela demonstra compreensão pelas atitudes do pai de não incentivo ao seu estudo, "também ele era analfabeto, não tinha como ele valorizar o estudo", reconhece ter errado na educação dos filhos, mas vê isto como um 
aprendizado,"eu errei, estava aprendendo a ser mãe", e, apesar disso, se vê como uma"batalhadora"e diz que se sente realizada pelo que alcançou em sua vida.

Aliada a todos esses fatores, encontra-se a disposição em estabelecer propósitos de vida: "A" verbalizou querer continuar a dar aulas, a cuidar da saúde (o que demonstra a preocupação de permanecer viva) e a se relacionar com os filhos. Os comportamentos que levam o indivíduo a alcançar seus propósitos são fortemente reforçados e estabelecem no indivíduo uma posição ativa, que o auxilia em todas as etapas da vida, principalmente durante a velhice, impedindo-o de ver a vida sem significados, sem propósitos.

Assim, a participante demonstrou possuir um senso de crescimento contínuo e de desenvolvimento pessoal e, mesmo com o envelhecimento, considera que ainda está em processo de aprendizagem: "é sempre válido aprender coisas novas". Tal habilidade é relevante porque ela tenderá a aprender novos repertórios caso ocorram mudanças no ambiente em que se encontra.

A variável crença religiosa também foi identificada como um ponto fortemente presente na vida da entrevistada. A preocupação com a proximidade da morte também foi encontrada pelas entrevistadoras: "agora cada vez se chega mais perto da morte ... quando se nasce, já começa a morrer". De acordo com Goldstein e Neri (1993), vários teóricos do desenvolvimento afirmam que os comportamentos religiosos aumentam a partir da meia idade. A religiosidade na vida de "A" parece ter a função de atuar como apoio, pois pode diminuir a freqüência de se pensar sobre a morte. Segundo Fraiman (1995, p.120):

... a partir da meia idade, com a maior consciência do tempo, perda acentuada de vigor físico, aliada à possibilidade de surgimento de doenças crônicas e falecimento de parentes e amigos, inclusive da mesma faixa etária, o ser humano entra em contato mais íntimo com a morte.

No entanto, apesar da forte religiosidade, não se verifica em " $A$ " uma posição passiva, de conformismo diante da vida, pelo contrário, ela se mostra uma pessoa ativa e autônoma.

\section{Conclusão}

Segundo Skinner e Vaughan (1985), o que levamos para a velhice são as habilidades que desenvolvemos antes de atingi-la e o que aprendemos ao observar e interagir com idosos. Com este estudo de caso foi possível perceber que os comportamentos que "A" desenvolveu em sua história de vida são as habilidades que ela apresenta hoje ao entrar na terceira idade, que podem facilitar ou dificultar seu bem-estar nessa fase. De acordo com Freire (2000), a presença de variáveis como autonomia, auto-aceitação, redes de apoio, propósitos de vida e crença religiosa aumenta a chance de o indivíduo ter uma velhice mais bem-sucedida. Para Haydu (2003), o grande desafio dos organismos vivos é adaptar-se às condições que o meio Ihe oferece e sobreviver. Apesar das condições nem sempre favoráveis para a entrevistada, como os empecilhos para estudar, " $\mathrm{A}$ " desenvolveu comportamentos adaptativos que the permitiram fazê-lo, como andar longas distâncias até a escola e trabalhar desde a infância.

Além disso, ela possui grande parte dos aspectos que facilitam a adaptação do indivíduo ao envelhecimento, como, por exemplo, autonomia, redes de apoio, auto-aceitação, propósitos de vida e crença religiosa, e, em contrapartida, não apresenta os aspectos que dificultam o envelhecimento, como agarrar-se ao passado, negação da velhice, isolamento e postura religiosa conformista. Tais habilidades podem agir como facilitadores para que " $\mathrm{A}$ " lide com as mudanças que aparecem nessa fase. Desse modo, ela assume uma postura ativa, interagindo e modificando seu ambiente com um suporte social e afetivo. Cabe ressaltar que se tais variáveis e habilidades estiverem presentes, facilitarão não só a velhice, como qualquer outro período da vida do indivíduo.

A preocupação deste estudo foi realizar uma leitura, ainda que incipiente, de acordo com a análise do comportamento, tendo em vista poucas publicações sobre o tema nessa área. Embora o comportamento seja produto de múltiplas causas, sendo muitas delas obscuras, determinados aspectos gerais podem contribuir para que indivíduos que estejam passando pelo processo de envelhecimento o façam de forma mais adequada.

\section{Referências}

Baltes, M., Silverberg, S. (1995). A dinâmica dependência-autonomia no curso de vida. In A. L. Néri. Psicologia do envelhecimento (pp.73-110). Campinas: Papirus. 
Cavalcante, A. M. (2002). Psiquiatria on line Brasil: a psicologia do idoso. Acessado em junho 23, 2005, disponível em: http://www.polbr.med.br/arquivo/mour0502.htm

Fraiman, A. (1995). Coisas da Idade. São Paulo: Editora Gente.

Freire, S. A. (2000). Envelhecimento bem-sucedido e bem-estar psicológico. In A. L. Neri \& S. A. Freire (Orgs.), Epor falar em boa velhice (pp.21-30). Campinas: Papirus.

Goldstein, L. L. (2002). No comando da própria vida: a importância de crenças e comportamentos de controle para o bem-estar na velhice. In A. L. Neri \& S. A. Freire (Orgs.), E por falar em boa velhice (pp.55-66). Campinas: Papirus.

Goldstein, L. L., Neri, A. L. (1993). Tudo bem, graças a Deus. Religiosidade e satisfação na maturidade e na velhice. In A. L. Neri. Qualidade de vida e idade madura (pp.109-133). Campinas: Papirus.

Guilhardi, H. J. (2002). Auto-estima, autoconfiança e responsabilidade. In M. Z. S. Brandão et al. Comportamento humano: tudo ou quase tudo que você queria saber paraviver melhor (pp.63-98). Santo André: Editora Esetec.

Haydu, V. B. (2003). Aprendizagem: desenvolvimento e adaptação. In M. A. T. Zamberlan (Org.), Psicologia e prevenção: modelos de intervenção na infância e adolescência (pp.103-139). Londrina: Eduel.

Neri, A. L. (1995). Psicologia do envelhecimento: uma área emergente. In Psicologia do envelhecimento (pp.13-40). Campinas: Papirus.

Skinner, B. F., \& Vaughan, M. E. (1985). Viva bem a velhice: aprendendo a programar sua vida. São Paulo: Summus.

Starling, R. R. (1999). Contingências de reforçamento vagamente definidas: construindo prematuramente a velhice. In R. R. Kerbaury \& R. C. Wielensky. Sobre 0 comportamento e cognição (pp.221-229). Santo André: Arbites.

Tavares, S. S., Neri, A. L., \& Cupertino, A. P. (2004). Saúde emocional após a aposentadoria. In A. L. Néri, M. S. Yassuda \& M. Cachioni (Orgs.), Velhice bem-sucedida: aspectos afetivos e cognitivos (pp.91-110). Campinas: Papirus.

Recebido em: 24/8/2005

Versão final reapresentada em: 2/1/2006

Aprovado em: 13/2/2006 